\title{
Genetics and epigenetics in the pathogenesis of primary biliary cholangitis
}

\author{
Satoru Joshita ${ }^{1,2} \mathbb{C} \cdot$ Takeji Umemura $^{1,2} \cdot$ Eiji Tanaka $^{1} \cdot$ Masao Ota $^{1}$
}

Received: 30 October 2017 / Accepted: 5 November 2017 / Published online: 20 November 2017

(C) Japanese Society of Gastroenterology 2017

\begin{abstract}
Primary biliary cholangitis (PBC) is a chronic, slowly progressive cholestatic autoimmune liver disease predominantly afflicting women. PBC is characterized by the presence of disease-specific antimitochondrial antibodies and the histological destruction of intrahepatic bile ducts, which eventually lead to cirrhosis and hepatic failure. Fortunately, ursodeoxycholic acid therapy has improved the outcome of the vast majority of PBC cases. Although the etiology of PBC has not yet been elucidated, human leukocyte antigen (HLA) class II alleles have been consistently associated with disease onset for decades. PBC patients may also have genetically determined risk factors in non-HLA regions. Meanwhile, exposure to environmental factors, such as infectious diseases and harmful chemicals, can produce epigenetic alterations in some individuals and subsequent PBC onset. In this review, we describe the influence of HLA alleles and other gene polymorphisms on PBC along with the results of genome-wide association studies on this disease and its future prospects in terms of epigenetics.
\end{abstract}

Keywords Primary biliary cholangitis $\cdot$ Human leukocyte antigen $\cdot$ Genome-wide association study $\cdot$ Interleukin 12 signaling pathway

\section{Introduction}

Primary biliary cholangitis (PBC) is a chronic and slowly progressive liver-specific autoimmune disease characterized by female preponderance and destruction of intrahepatic bile ducts that eventually leads to cirrhosis and hepatic failure [1-4]. The prevalence of PBC ranges from $20-40$ cases per 100,000 individuals [2, 3, 5], although the number of patients with $\mathrm{PBC}$, specifically asymptomatic $\mathrm{PBC}$, is on the rise owing mainly to increased awareness and earlier

Satoru Joshita

joshita@shinshu-u.ac.jp

Masao Ota

otamasao@shinshu-u.ac.jp

Takeji Umemura

tumemura@shinshu-u.ac.jp

Eiji Tanaka

etanaka@shinshu-u.ac.jp

1 Department of Medicine, Division of Gastroenterology and Hepatology, Shinshu University School of Medicine, 3-1-1 Asahi, Matsumoto, Nagano 390-8621, Japan

2 Research Center for Next Generation Medicine, Shinshu University, Matsumoto, Japan detection by disease-specific antimitochondrial antibodies. The prognosis of patients with $\mathrm{PBC}$ has improved greatly over the past two decades thanks to earlier diagnosis and the widespread use of ursodeoxycholic acid (UDCA), which is currently the most effective treatment for PBC $[4,6]$ according to most guidelines [7, 8]. The terminology of PBC was changed from primary biliary cirrhosis to more accurately reflect the disorder and its natural history [9-13]. However, some cases still exhibit disease progression via completely unknown mechanisms.

The precise cause of PBC is unclear, but as with other autoimmune diseases, is likely related to both genetic susceptibility and environmental factors. Genetic factors are considered to play a prominent role in disease onset as higher concordance rates in monozygotic twins than in dizygotic twins and familial clustering of patients with PBC have been demonstrated in numerous family and population studies [14-19]. PBC is therefore presumed to be a multifactorial polygenic condition caused by allelic triggers and environmental influences in genetically susceptible individuals along with other epigenetic mechanisms [20,21].

In the present review, we summarize the literature on (1) human leukocyte antigen (HLA) involvement in PBC onset, (2) genome-wide association study (GWAS) findings from 
North American, European, Japanese, and Chinese populations, and (3) epigenetics to explore the disease pathways involved in PBC pathogenesis.

\section{Microsatellites and single nucleotide polymorphisms (SNPs)}

Microsatellites ranging in length from 2- to 13-base-pair nucleotides are subcategories of typically 5-50 tandem repeats that make up genomic repetitive regions. Tandem repeats are evolutionarily relevant due to their instability since they mutate at rates between $10^{3}$ and $10^{6}$ per cell generation, i.e., up to 10 orders of magnitude greater than point mutations [22]. Microsatellites are used in genetic linkage analyses to locate genes or mutations responsible for a wide variety of diseases. Several reports have described an association between microsatellites and PBC susceptibility [23-26]. However, there are differences between the candidate genes indicated by microsatellite markers and those reported by SNP-based studies or by GWASs, which is likely attributable the intermarker distances among microsatellites that contain new or previously unidentified genes responsible for the pathogenesis of PBC.

The modern unit of genetic variation is now the SNP. SNPs are single base-pair changes in the DNA sequence that occur at high frequencies in the human genome [27]. SNPs may fall within the coding sequences of genes, noncoding regions of genes, or in intergenic regions. Although a single SNP may cause a Mendelian disease, SNPs do not usually function individually and work in coordination with other SNPs to produce clinical manifestations in complex diseases. In this aspect, association studies can determine whether a genetic variant is associated with $\mathrm{PBC}$ or not. To date, many significant susceptibility SNPs, such as CTLA4, TNF- $a$, STAT4, PTPN22, VDR, Clec16A, SOCS1, and SPIB, have been identified over the past two decades using candidate gene methods [28-33].

\section{Associations between HLA and PBC susceptibility}

Among the SNPs previously reported to be associated with susceptibility to PBC, only HLA has been consistently linked to the disease in distinct patient cohorts across ethnicities as depicted by many significant dots on genome-wide Manhattan plots of GWASs [34-43].

The HLA complex on chromosomal position 6p21 contains the most polymorphic genes in the human genome [44]. HLA genes play an essential role in numerous infectious and autoimmune diseases, such as autoimmune hepatitis as previously reviewed [45]. The products of the classical HLA class I $(A, B$, and $C)$ and class II $(D R, D Q$, and $D P)$ genes include cell-surface glycoproteins involved in the binding and presentation of self or non-self peptides to T-cell receptors. Class I molecules are recognized by $\mathrm{CD} 8^{+}$cytotoxic $\mathrm{T}$ cells presenting endogenous peptides, while class II molecules are recognized by $\mathrm{CD} 4^{+}$helper $\mathrm{T}$ cells presenting processed peptides from exogenous pathogens. The extent of endogenous and exogenous peptide binding to HLA molecules depends on allelic polymorphisms. Additionally, HLA class I and II molecules have functional roles in protein interactions, transcription regulation involved in the inflammatory response, and natural killer cell-cytokine interactions as part of acquired and innate immunities.

HLA polymorphisms have been extensively studied in immune-mediated diseases to reveal associations among specific alleles and ankylosing spondylitis, Behçet's disease, psoriasis, multiple sclerosis, insulin-dependent diabetes mellitus, systemic lupus erythematosus, inflammatory bowel disease, rheumatoid arthritis, narcolepsy, autoimmune hepatitis, and autoimmune pancreatitis among others. Early investigations on associations between HLA polymorphisms and $\mathrm{PBC}$ were carried out $>25$ years ago [46]. Based on their findings, subsequent cumulative studies have provided evidence that $\mathrm{PBC}$ is associated with $D R B 1 * 08$ as a predisposing allele and $D R B 1 * 11$ and $D R B 1 * 13$ as protective alleles $[47,48]$. Li et al. conducted a meta-analysis to assess for relationships between HLA class II and disease susceptibility to PBC and demonstrated that HLA DR*07 and *08 alleles were risk factors for $\mathrm{PBC}$ in certain populations, while $D R * 11, * 12, * 13$, and $* 15$ alleles were protective factors [49].

Five key reports [47, 50-53] on the association between HLA haplotype and PBC susceptibility or resistance are summarized in Table 1. It was noteworthy that $H L A D R^{*} 08$ alleles were related to disease susceptibility and $H L A$ $D R B 1 * 11$ and $* 13$ alleles conferred disease protection in haplotype analyses across all ethnicities apart from a Sardinian population [52]. Four major differences were indicated to have functional importance in the amino acid residues encoded by the different associated alleles, including the encoding of glycine-13, tyrosine-16, and leucine- 74 by $H L A$ $D R B 1 * 0801$ versus that of serine- 13 and phenylalanine- 47 by most $H L A D R B 1 * 11$ and $H L A D R B 1 * 13$ alleles, respectively [47]. Moreover, $H L A D R B 1 * 11$ alleles have been identified in several infectious diseases, such as hepatitis $\mathrm{C}$ virus [54], human papilloma virus [55], and human immunodeficiency virus [56], while $H L A D R B 1 * 13$ alleles have been associated with hepatitis B virus [57] and human papilloma virus [58]. Molecular mimicry has been widely suspected to initiate autoimmunity in patients with PBC. Since protective HLA class II alleles also play a functional role in blocking virus infection, one of the pathogenic mechanisms in PBC may be viral insult. Retrovirus infection was reportedly 
Table 1 HLA haplotype associations with PBC

\begin{tabular}{|c|c|c|c|c|c|c|c|}
\hline Study & Year & Population & PBC patients & Controls & HLA allele & OR $(95 \% \mathrm{CI})$ & $p$-value \\
\hline \multicolumn{8}{|l|}{ Susceptibility } \\
\hline \multirow[t]{2}{*}{ Donaldson et al. [47] } & 2006 & UK & 412 & 236 & $\begin{array}{l}\text { DRB1*08:01-DQA1*04*01- } \\
\text { DQB1*04:02 }\end{array}$ & $2.90(1.45-5.82)$ & 0.0027 \\
\hline & & Italian & 80 & 95 & $\begin{array}{l}\text { DRB1*08:01-DQA1*04*01- } \\
\text { DQB1*04:02 }\end{array}$ & $3.41(1.36-8.52)$ & 0.0086 \\
\hline \multirow[t]{2}{*}{ Umemura et al. [50] } & 2012 & Japanese & 229 & 523 & DRB1*08:03-DQB1*06:01 & $2.22(1.53-3.20)$ & 0.000025 \\
\hline & & & & & DRB1*04:05-DQB1*04:01 & $1.38(10.2-1.87)$ & 0.044 \\
\hline \multirow[t]{2}{*}{ Zhao et al. [51] } & 2014 & Chinese & 145 & 500 & DRB1*08:03-DQB1*06:01 & $3.17(1.91-5.23)$ & $<0.0001$ \\
\hline & & & & & DRB1*07:01-DQB1*02:02 & $1.85(1.20-2.83)$ & 0.005 \\
\hline Clemente et al. [52] & 2017 & Sardinian & 20 & 89 & DRB1*03:01-DQB1*02:01 & $3.02(1.51-6.05)$ & $<0.05$ \\
\hline \multirow[t]{2}{*}{ Yasunami et al. [53] } & 2017 & Japanese & 1199 & 1193 & DRB1*08:03-DQB1*06:01 & $1.77(1.43-2.18)$ & $7.82 \times 10^{-8}$ \\
\hline & & & & & DRB1*14:05-DQB1*04:01 & $1.49(1.24-1.79)$ & $01.44 \times 10^{-5}$ \\
\hline \multicolumn{8}{|l|}{ Protective } \\
\hline \multirow[t]{2}{*}{ Donaldson et al. [47] } & 2006 & Italian & 21 & 46 & $\begin{array}{l}\text { DRB1*11:01-DQA1*05:01- } \\
\text { DQB1*03:01 }\end{array}$ & $0.47(0.27-0.83)$ & 0.086 \\
\hline & & Italian & 3 & 12 & $\begin{array}{l}\text { DRB1*13:01-DQA1*01:03- } \\
\text { DQB1*06:03 }\end{array}$ & $0.28(0.08-0.95)$ & 0.0041 \\
\hline \multirow[t]{2}{*}{ Umemura et al. [50] } & 2012 & Japanese & 229 & 523 & DRB1*13:02-DQB1*06:04 & $0.27(0.12-0.60)$ & 0.00093 \\
\hline & & & & & DRB1*11:01-DQB1*03:01 & $0.37(0.15-0.88)$ & 0.03 \\
\hline Zhao et al. [51] & 2014 & Chinese & 145 & 500 & DRB1*12:02-DQB1*03:01 & $0.43(0.22-0.86)$ & 0.015 \\
\hline \multirow[t]{3}{*}{ Yasunami et al. [53] } & 2017 & Japanese & 1199 & 1193 & DRB1*13:02-DQB1*06:04 & $0.19(0.13-0.27)$ & $1.84 \times 10^{-22}$ \\
\hline & & & & & DRB1*14:03-DQB1*03:01 & $0.21(0.09-0.49)$ & $5.1 \times 10^{-5}$ \\
\hline & & & & & not (DRB1*14:03)-DQB $1 * 03: 01$ & $0.54(0.43-0.68)$ & $8.54 \times 10^{-8}$ \\
\hline
\end{tabular}

OR odds ratio, $C I$ confidence interval

associated with PBC, although these findings have not yet been replicated [59]. Lastly, it should be noted that individuals harboring the above haplotypes constitute only a minority of patients with $\mathrm{PBC}$, suggesting that other candidate genes and environmental factors evoke PBC pathogenesis as well.

\section{GWASs on PBC}

A gene-specific, candidate-driven approach that specifically tests a small number of pre-specified genetic regions has limitations in finding pathogenic genes of such multi-factorial diseases as PBC. GWASs typically focus on associations between SNPs and traits like major human diseases in investigations of the entire genome. There have been extensive GWASs aiming to clarify genetic susceptibility in patients with PBC. To date, seven GWASs [34-38, 42, 43], two Illumina immunochip studies [39, 40], and one genome-wide meta-analysis (GWMA) [41] on PBC have been documented in well-characterized cohorts in North American, European, Japanese, and recently Chinese populations (Table 2). All studies confirmed that the HLA class II domain showed the strongest association with $\mathrm{PBC}$ susceptibility, particularly at the HLA-DRBI, $-D Q A 1$, and $-D Q B 1$ loci, and indicated the involvement of HLA class II polymorphisms in the pathogenesis of PBC across ethnicities. However, HLA alone does not explain the entire genetic predisposition to $\mathrm{PBC}$, mainly since $80-90 \%$ of patients with the disease do not carry the most common HLA susceptibility alleles. In this regard, other genes apart from HLA loci are suggested to contribute to disease development. At present, GWASs have identified 44 non-HLA PBC predisposition loci at a genome-wide level of significance (Table 3 ).

The first GWAS [34] in a North American cohort revealed a significant association between $P B C$ and genetic variants at interleukin (IL) $12 A$ and IL12RB2, respectively encoding IL-12 p35 and IL-12 receptor $\beta 2$. The second GWAS [36] confirmed the existence of additional risk loci, including interferon regulatory factor 5 (IRF5), transportin 3 (TNPO3), and transcription factor Spi-B (SPIB) encoding a transcription factor involved in B-cell receptor signaling and T-cell lineage decisions. A subsequent GWAS from Japan showed that tumor necrosis factor superfamily, member 15 (TNFSF15) and POU domain class 2-associating factor 1 (POU2AF1) genes also constituted novel risk loci in Japanese patients with PBC, and a recent GWAS of a Han Chinese population found the highest association was between TNFSF 15 and PBC. The ILI2A and IL12RB2 loci were not significantly 
Table 2 GWASs on PBC

\begin{tabular}{|c|c|c|c|c|c|c|c|c|c|}
\hline Study & Year & Platform & Population & $\begin{array}{l}\text { Total } \\
\text { patients }\end{array}$ & Controls & $\begin{array}{l}\text { GWAS } \\
\text { patients }\end{array}$ & Controls & $\begin{array}{l}\text { Validation } \\
\text { patients }\end{array}$ & Controls \\
\hline Hirschfield et al. [34] & 2009 & $\begin{array}{l}\text { Illumina HumanHap } \\
370\end{array}$ & $\begin{array}{l}\text { Caucasian from North } \\
\text { America }\end{array}$ & 1031 & 2713 & 505 & 1507 & 526 & 1206 \\
\hline Hirschfield et al. [35] & 2010 & $\begin{array}{l}\text { Illumina HumanHap } \\
370\end{array}$ & European descent & 1351 & 4700 & 494 & 1502 & 857 & 3198 \\
\hline Liu et al. [36] & 2010 & Illumina $610 \mathrm{~K}$ & Italian & 945 & 4651 & & & & \\
\hline Mells et al. [37] & 2011 & Illumina $660 \mathrm{~W}$-Quad & UK, Canada & 1840 & 5163 & 1840 & 5163 & 620 & 2514 \\
\hline Nakamura et al. [38] & 2012 & Affymetrix Axiom & Japanese & 1274 & 1091 & 487 & 476 & 787 & 615 \\
\hline Juran et al. [39] & 2012 & Immunochip & $\begin{array}{l}\text { European descent from } \\
\text { Canada, USA, and } \\
\text { Italy }\end{array}$ & 2216 & 5594 & & & & \\
\hline Liu et al. [40] & 2012 & Immunochip & UK & 2861 & 8514 & & & & \\
\hline Cordell et al. [41] & 2015 & GWMA & Canada, USA, Italy, UK & 2764 & 10,475 & 2764 & 10,475 & 3716 & 4261 \\
\hline Kawashima et al. [42] & 2017 & Affymetrix Axiom & Japanese & 894 & 1029 & 894 & 1029 & 512 & 6512 \\
\hline Qiu et al. [43] & 2017 & $\begin{array}{l}\text { Illumina HumanOm- } \\
\text { niZhongHua-8 }\end{array}$ & Han Chinese & 1122 & 4036 & 1122 & 4036 & 907 & 2127 \\
\hline
\end{tabular}

Hirschfield et al. study [35] used 494 patients and 1502 controls included in their previous study [34]. Liu et al. [40] study used 1,838 patients and 2356 controls included in their previous PBC GWAS [37]. Kawashima et al. study combined data from a previous GWAS data [38]

associated with PBC in the Asian cohorts. This discrepancy among ethnicities indicated important differences in the pathogenesis of PBC despite several common key molecules and pathways, such as the IL-12 pathway to induce Th1 polarization of $\mathrm{CD} 4^{+} \mathrm{T}$ cells. TNFSF15 interacts with death receptor 3 (DR3) not only to promote T-cell expansion, but also to induce apoptosis in cells that overexpress DR3, which can synergistically interact with IL-12 and IL-18 to promote interferon-gamma production [60]. Thus, the IL-12 signaling pathway appears to be a key player in the pathogenesis of PBC worldwide. To support this hypothesis, STAT4, which factors prominently in IL-12 signal transduction polymorphisms, was associated with susceptibility in Japanese and Han Chinese PBC patients $[38,43]$.

The IL-12 pathway has also been associated with animal models of PBC and a pediatric case of a congenital IL-12 deficiency that developed PBC [61]. Although antibodies or drugs targeting the IL-12 pathway would seem to be effective, clinical trials using ustekinumab, a human monoclonal antibody directed against IL-12 and IL-23, failed to produce clinical effects in phase II trials [62]. One reason explaining this disconnection between GWAS and clinical testing results may be that clinicians typically encounter patients who have already become complicated with cholestasis; in fact, the immunological destruction of cholangiocytes occurs in the very early stages of PBC. Accordingly, the mechanisms of disease progression should also be addressed to halt the deterioration of disease status and afford PBC patients an improved prognosis. We are now at the next stage of how genetic findings can be translated into the clinical setting.

It is particularly interesting that many genes implicated in PBC pathogenesis by GWASs have also been reported in other immune-mediated disorders, such as systemic lupus erythematosus, systemic sclerosis, and Sjögren's syndrome (Table 3), suggesting genetic overlap among autoimmune disorders and the existence of substantial pleiotropy, i.e., one gene leading to two or more seemingly unrelated disease phenotypes. Therefore, on a larger scale, understanding the mechanisms involved in the onset and progression of certain other autoimmune diseases may correspondingly shed light on those in PBC.

Lastly, it is noteworthy that Juran et al. identified riskconferring epistatic interactions between ILI2RB2 and IRF5 loci [39] as well as between CTLA4 and TNF $\alpha$ loci [63] in the pre-GWAS era. Epistatic interactions between genes in the pathogenesis of PBC revealed by GWASs also merit exploration in future studies.

\section{Epigenetics on PBC}

Epigenetics is the study of stable heritable changes in gene function that do not involve alterations in DNA sequence. Several molecular mechanisms are involved in epigenetic modification, including DNA methylation, histone modification, and modification via noncoding RNA. Although GWASs have identified several candidate genes implicated in PBC pathogenesis, they are thought to explain $<20 \%$ of 
Table 3 Non-HLA risk loci identified through GWASs to be associated with PBC at the genome-wide level of significance

\begin{tabular}{|c|c|c|c|c|c|c|c|}
\hline Chromosome & Locus & Study (reference\#) & SNP & OR & $p$ value & Candidate gene(s) & Disease(s) with shared risk loci \\
\hline \multirow[t]{4}{*}{1} & $1 \mathrm{p} 13$ & {$[43]$} & rs 2300747 & 1.30 & $4.54 \mathrm{E}-08$ & $C D 58$ & MS, neuromyelitis \\
\hline & $1 \mathrm{p} 31$ & {$[40]$} & rs72678531 & 1.61 & $2.47 \mathrm{E}-38$ & $I L 12 R B 2$ & $\mathrm{BD}, \mathrm{MS}$ \\
\hline & $1 \mathrm{p} 36$ & {$[35]$} & rs 3748816 & 1.33 & $3.15 \mathrm{E}-08$ & $M M E L 1$ & MS \\
\hline & $1 \mathrm{q} 31$ & {$[37]$} & rs 12134279 & 1.34 & $2.06 \mathrm{E}-14$ & $D E N N D 1 B$ & $\mathrm{CD}$ \\
\hline \multirow[t]{6}{*}{2} & $2 q 12$ & [41] & rs 12712133 & 1.14 & $5.19 \mathrm{E}-09$ & $I L 1 R L 1, I L 1 R L 2$, & \\
\hline & $2 q 32$ & [37] & rs 10931468 & 1.50 & $2.35 \mathrm{E}-19$ & STAT4, STAT1 & RA, SLE, SS, IBD, SSc, BD \\
\hline & $2 q 32$ & {$[43]$} & rs 10168266 & 1.31 & $5.82 \mathrm{E}-08$ & STAT4, STAT1 & RA, SLE, SS, IBD, SSc, BD \\
\hline & $2 q 33$ & [43] & rs4675369 & 1.37 & $6.56 \mathrm{E}-11$ & CD28, CRLA4, ICOS & \\
\hline & $2 q 33$ & [43] & rs7599230 & 1.37 & $6.56 \mathrm{E}-11$ & CD28, CRLA4, ICOS & \\
\hline & $2 q 36$ & [41] & rs4973341 & 1.22 & $2.34 \mathrm{E}-10$ & CCL2O & \\
\hline \multirow[t]{3}{*}{3} & $3 \mathrm{p} 24$ & {$[37]$} & rs1372072 & 1.20 & $2.28 \mathrm{E}-08$ & PLCL2 & RA \\
\hline & $3 q 13$ & {$[40]$} & rs2293370 & 1.39 & $6.84 \mathrm{E}-16$ & CD80 & MS, SLE, celiac \\
\hline & $3 q 25$ & {$[40]$} & rs 2366643 & 1.35 & $3.92 \mathrm{E}-22$ & $I L 12 A$ & Celiac \\
\hline \multirow[t]{2}{*}{4} & $4 \mathrm{p} 16$ & [41] & rs11724804 & 1.22 & $9.01 \mathrm{E}-12$ & $D G K Q$ & \\
\hline & $4 q 24$ & {$[37]$} & rs7665090 & 1.26 & $8.48 \mathrm{E}-14$ & $N F K B 1$ & $\mathrm{UC}$ \\
\hline \multirow[t]{4}{*}{5} & $5 \mathrm{p} 13$ & [40] & rs6871748 & 1.30 & $2.26 \mathrm{E}-13$ & $I L 7 R$ & MS, UC \\
\hline & $5 \mathrm{p} 13$ & [42] & rs6897932 & 1.52 & $5.72 \mathrm{E}-09$ & $I L 7 R$ & MS, UC \\
\hline & $5 q 21$ & {$[41]$} & rs526231 & 1.15 & $1.14 \mathrm{E}-08$ & C5orf30 & \\
\hline & $5 q 33$ & [41] & rs 2546890 & 1.15 & $1.06 \mathrm{E}-10$ & $I L 12 B, L O C 285626$ & Proriasis \\
\hline 6 & $6 q 23$ & {$[41]$} & rs6933404 & 1.18 & $1.27 \mathrm{E}-10$ & OLIG3, TNFAIP3 & RA \\
\hline \multirow[t]{2}{*}{7} & $7 \mathrm{p} 14$ & [37] & rs6974491 & 1.25 & $4.44 \mathrm{E}-08$ & ELMO1 & RA, celiac \\
\hline & $7 q 32$ & {$[40]$} & rs35188261 & 1.52 & $6.52 \mathrm{E}-22$ & IRF5 & RA, SLE, SSc, UC \\
\hline \multirow[t]{2}{*}{9} & 9 p32 & {$[38][42]$} & rs4979462 & 1.57 & $1.85 \mathrm{E}-14$ & TNFSF 15 & $\mathrm{UC}, \mathrm{CD}$ \\
\hline & 9 p32 & [43] & rs4979467 & 1.40 & $8.28 \mathrm{E}-12$ & TNFSF15, TNFSF8 & $\mathrm{UC}, \mathrm{CD}$ \\
\hline \multirow[t]{5}{*}{11} & $11 \mathrm{q} 13$ & [37] & rs538147 & 1.23 & $2.06 \mathrm{E}-10$ & RPS6KA4 & IBD \\
\hline & $11 \mathrm{q} 23$ & {$[38][42]$} & rs4938534 & 1.38 & $3.27 \mathrm{E}-08$ & POU $2 A F 1$ & \\
\hline & $11 \mathrm{q} 23$ & [43] & rs77871618 & 1.55 & $9.12 \mathrm{E}-14$ & CXCR5, DDX6 & RA, IBD, celiac \\
\hline & $11 \mathrm{q} 23$ & {$[40]$} & rs80065107 & 1.39 & $7.20 \mathrm{E}-16$ & $C X C R 5, D D X 6$ & RA, IBD, celiac \\
\hline & $11 \mathrm{q} 24$ & {$[42]$} & rs12574073 & 1.33 & $1.09 \mathrm{E}-07$ & ETS1 & AS \\
\hline \multirow[t]{2}{*}{12} & $12 \mathrm{p} 13$ & [40] & rs 1800693 & 1.27 & $1.18 \mathrm{E}-14$ & TNFRSF1A, LTBR & MS \\
\hline & $12 q 24$ & {$[40]$} & rs11065979 & 1.20 & $2.87 \mathrm{E}-09$ & $\mathrm{SH} 2 \mathrm{~B} 3$ & RA, T1DM, hyperthyroidism, celiac \\
\hline 13 & $13 q 14$ & {$[39][40]$} & rs 3862738 & 1.33 & $2.18 \mathrm{E}-08$ & TNFSF 11 & $\mathrm{CD}$ \\
\hline \multirow[t]{2}{*}{14} & $14 q 24$ & {$[40]$} & rs911263 & 1.26 & $9.95 \mathrm{E}-11$ & $R A D 51 B$ & RA \\
\hline & $14 q 32$ & {$[37]$} & rs8017161 & 1.22 & $2.61 \mathrm{E}-13$ & TNFAIP2 & \\
\hline \multirow[t]{3}{*}{16} & $16 \mathrm{p} 12$ & [42] & rs 3785396 & 1.35 & $7.10 \mathrm{E}-08$ & $P R K C B$ & \\
\hline & $16 \mathrm{p} 13$ & {$[40]$} & rs 12708715 & 1.29 & $2.19 \mathrm{E}-13$ & CLEC16A, SOCS1 & MS, UC, T1DM \\
\hline & $16 \mathrm{q} 24$ & {$[37]$} & rs11117432 & 1.31 & $4.66 \mathrm{E}-11$ & $I R F 8$ & $\mathrm{MS}, \mathrm{IBD}, \mathrm{RA}, \mathrm{SSc}$ \\
\hline \multirow[t]{4}{*}{17} & $17 \mathrm{q} 12$ & {$[40]$} & rs17564829 & 1.26 & $6.05 \mathrm{E}-14$ & $I K Z F 3$ & $\mathrm{UC}, \mathrm{CD}, \mathrm{RA}, \mathrm{T} 1 \mathrm{DM}$ \\
\hline & $17 \mathrm{q} 12$ & {$[42]$} & rs9303277 & 1.43 & $8.37 \mathrm{E}-11$ & $I K Z F 3$ & $\mathrm{UC}, \mathrm{CD}, \mathrm{RA}, \mathrm{T} 1 \mathrm{DM}$ \\
\hline & $17 \mathrm{q} 12$ & {$[43]$} & rs9635726 & 1.38 & $6.42 \mathrm{E}-11$ & Multiple genes & \\
\hline & $17 q 21$ & {$[40]$} & rs 17564829 & 1.25 & $2.15 \mathrm{E}-09$ & MAPT & \\
\hline \multirow[t]{2}{*}{19} & $19 \mathrm{p} 12$ & {$[40]$} & rs34536443 & 1.91 & $1.23 \mathrm{E}-12$ & $T Y K 2$ & IBD, RA, SLE, psoriasis, T1DM \\
\hline & $19 \mathrm{q} 13$ & [36] & rs 3745516 & 1.46 & $7.97 \mathrm{E}-11$ & $S P I B$ & \\
\hline 22 & $22 q 13$ & [40] & rs2267407 & 1.29 & $1.29 \mathrm{E}-13$ & SYNGRl & \\
\hline
\end{tabular}

$O R$ odds ratio, $M S$ multiple sclerosis, $B D$ Behçet's disease, $C D$ Crohn's disease, $R A$ rheumatoid arthritis, $S L E$ systemic lupus erythematosus, $S S$ Sjögren's syndrome, $I B D$ inflammatory bowel disease, $S S C$ systemic sclerosis, $U C$ ulcerative colitis, $A S$ ankylosing spondylitis, $T 1 D M$ type 1 diabetes mellitus 
heritability in PBC; indeed, a relatively low concordance of PBC was found in an earlier study of monozygotic and dizygotic twins [19]. Epigenetics may also have an important role in symptoms, disease progress rate, biochemical response to UDCA therapy, and other disease phenotypes, implying that patients at genetic risk for PBC may manifest the disease via epigenetic factors as well. Case-control studies have identified potential exposure sources in PBC, such as urinary tract infection, smoking and cigarette smoke, and exogenous estrogens [15]. How these factors are molecularly involved in PBC onset remains unclear. Elsewhere, it was reported that $\mathrm{X}$-chromosome gene expression instability might also participate in female predominance in the disease $[64,65]$, and that monozygotic twins and sisters discordant for PBC exhibited particular epigenetic differences [66]. These collectively support the notion that epigenetic factors influence the onset of PBC. Epigenetics has numerous and varied potential medical applications and may be able to uncover novel pathways for therapeutic discovery and intervention in $\mathrm{PBC}$.

\section{Conclusions and future directions}

The pathogenesis of PBC is incompletely understood but appears to involve genetic susceptibility and resistance alleles in HLA and other gene loci, with a possible overlap with several autoimmune diseases. It is also probable that genetically susceptible individuals develop PBC following exposure to environmental factors that trigger DNA methylation, histone modification, modification via noncoding RNA, and other epigenetic modifications. Consequently, both adaptive and innate immune responses result in portal inflammation and bile duct epithelial damage. In addition to susceptibility, the precise mechanisms of PBC progression should be addressed to improve patient prognosis and quality of life.

Acknowledgements We sincerely appreciate the financial support provided by Grants-in-Aid for Young Scientists (Kakenhi 16K21069) and the Promotion Project of Education, Research, and Medical care from Shinshu University Hospital. We also thank Mr. Trevor Ralph for his English editorial assistance.

\section{Compliance with ethical standards}

Conflict of interest: Satoru Joshita, Takeji Umemura, Eiji Tanaka, and Masao Ota declare that they have nothing to disclose regarding funding from industries or other conflicts of interest with respect to this manuscript.

Human/animal rights: This study does not include any data on human subjects.

Informed Consent: This study does not involve human subjects and does not require informed consent.

\section{References}

1. Talwalkar JA, Lindor KD. Primary biliary cirrhosis. Lancet. 2003;362:53-61.

2. Kim WR, Lindor KD, Locke GR 3rd, et al. Epidemiology and natural history of primary biliary cirrhosis in a US community. Gastroenterology. 2000;119:1631-6.

3. Lindor KD, Gershwin ME, Poupon R, et al. Primary biliary cirrhosis. Hepatology. 2009;50:291-308.

4. Joshita S, Umemura T, Ota M, et al. AST/platelet ratio index associates with progression to hepatic failure and correlates with histological fibrosis stage in Japanese patients with primary biliary cirrhosis. J Hepatol. 2014;61:1443-5.

5. Hirohara J, et al. Epidemiology and natural history in Japan. In: Ohira H, editors. Autoimmune liver diseases. Tokyo: Springer; 2014.

6. Umemura T, Joshita S, Sekiguchi T, et al. Serum wisteria floribunda agglutinin-positive Mac-2-binding protein level predicts liver fibrosis and prognosis in primary biliary cirrhosis. Am J Gastroenterol. 2015;110:857-64.

7. EASL Clinical Practice Guidelines. Management of cholestatic liver diseases. J Hepatol. 2009;51:237-67.

8. Guidelines for the management of primary biliary cirrhosis: The Intractable Hepatobiliary Disease Study Group supported by the Ministry of Health, Labour and Welfare of Japan. Hepatol Res 2014;44 Suppl S1:71-90.

9. Beuers U, Gershwin ME, Gish RG, et al. Changing nomenclature for PBC: from 'cirrhosis' to 'cholangitis'. Gastroenterology. 2015;149:1627-9.

10. Tanaka A, Takikawa H, Miwa H, et al. Changing nomenclature for PBC from "primary biliary cirrhosis" to "primary biliary cholangitis". Hepatol Res. 2016;46:725-6.

11. Tanaka A, Takikawa H, Mochida S, et al. Changing nomenclature for PBC from "primary biliary cirrhosis" to "primary biliary cholangitis". J Gastroenterol. 2016;51:748-9.

12. Beuers U, Gershwin ME, Gish RG, et al. Changing nomenclature for PBC: from 'cirrhosis' to 'cholangitis'. Hepatology. 2015;62:1620-2.

13. Beuers U, Gershwin ME, Gish RG, et al. Changing nomenclature for PBC: from 'cirrhosis' to 'cholangitis'. J Hepatol. 2015;63:1285-7.

14. Jones DE. Pathogenesis of primary biliary cirrhosis. J Hepatol. 2003;39:639-48.

15. Gershwin ME, Selmi C, Worman HJ, et al. Risk factors and comorbidities in primary biliary cirrhosis: a controlled interview-based study of 1032 patients. Hepatology. 2005;42:1194-202.

16. Kaplan MM, Gershwin ME. Primary biliary cirrhosis. N Engl J Med. 2005;353:1261-73.

17. Gershwin ME, Mackay IR. The causes of primary biliary cirrhosis: convenient and inconvenient truths. Hepatology. 2008;47:737-45.

18. Invernizzi P, Selmi C, Mackay IR, et al. From bases to basis: linking genetics to causation in primary biliary cirrhosis. Clin Gastroenterol Hepatol. 2005;3:401-10.

19. Selmi C, Mayo MJ, Bach N, et al. Primary biliary cirrhosis in monozygotic and dizygotic twins: genetics, epigenetics, and environment. Gastroenterology. 2004;127:485-92.

20. Xie YQ, Ma HD, Lian ZX. Epigenetics and primary biliary cirrhosis: a comprehensive review and implications for autoimmunity. Clin Rev Allergy Immunol. 2016;50:390-403.

21. Cheung AC, LaRusso NF, Gores GJ, et al. Epigenetics in the primary biliary cholangitis and primary sclerosing cholangitis. Semin Liver Dis. 2017;37:159-74. 
22. Vieira ML, Santini L, Diniz AL, et al. Microsatellite markers: what they mean and why they are so useful. Genet Mol Biol. 2016;39:312-28.

23. Graham AM, Dollinger MM, Howie SE, et al. Identification of novel alleles at a polymorphic microsatellite repeat region in the human NRAMP1 gene promoter: analysis of allele frequencies in primary biliary cirrhosis. J Med Genet. 2000;37:150-2.

24. Joshita S, Umemura T, Yoshizawa K, et al. A2BP1 as a novel susceptible gene for primary biliary cirrhosis in Japanese patients. Hum Immunol. 2010;71:520-4.

25. Lakatos PL, Bajnok E, Tornai I, et al. Insulin-like growth factor I gene microsatellite repeat, collagen type Ialpha1 gene Sp1 polymorphism, and bone disease in primary biliary cirrhosis. Eur J Gastroenterol Hepatol. 2004;16:753-9.

26. Yahagi K, Ueno Y, Nomura E, et al. Mapping of a disease susceptibility locus in the HLA region for primary biliary cirrhosis in Japan. Hepatol Res. 2007;37:270-5.

27. Abecasis GR, Altshuler D, Auton A, et al. A map of human genome variation from population-scale sequencing. Nature. 2010;467:1061-73.

28. Juran BD, Atkinson EJ, Schlicht EM, et al. Primary biliary cirrhosis is associated with a genetic variant in the $3^{\prime}$ flanking region of the CTLA4 gene. Gastroenterology. 2008;135:1200-6.

29. Tanaka A, Nezu S, Uegaki S, et al. Vitamin D receptor polymorphisms are associated with increased susceptibility to primary biliary cirrhosis in Japanese and Italian populations. J Hepatol 2009;50(6):1202-9. https://doi.org/10.1016/j.jhep.2009.01.015.

30. Joshita S, Umemura T, Yoshizawa K, et al. Association analysis of cytotoxic T-lymphocyte antigen 4 gene polymorphisms with primary biliary cirrhosis in Japanese patients. J Hepatol. 2010;53:537-41.

31. Joshita S, Umemura T, Nakamura M, et al. STAT4 gene polymorphisms are associated with susceptibility and ANA status in primary biliary cirrhosis. Dis Markers. 2014;2014:727393.

32. Umemura T, Joshita S, Yamazaki T, et al. Genetic association of PTPN22 polymorphisms with autoimmune hepatitis and primary biliary cholangitis in Japan. Sci Rep. 2016;6:29770.

33. Hirschfield GM, Xie G, Lu E, et al. Association of primary biliary cirrhosis with variants in the CLEC16A, SOCS1, SPIB and SIAE immunomodulatory genes. Genes Immun. 2012;13:328-35.

34. Hirschfield GM, Liu X, Xu C, et al. Primary biliary cirrhosis associated with HLA, IL12A, and IL12RB2 variants. N Engl J Med. 2009;360:2544-55.

35. Hirschfield GM, Liu X, Han Y, et al. Variants at IRF5-TNPO3, 17q12-21 and MMEL1 are associated with primary biliary cirrhosis. Nat Genet. 2010;42:655-7.

36. Liu X, Invernizzi P, Lu Y, et al. Genome-wide meta-analyses identify three loci associated with primary biliary cirrhosis. Nat Genet. 2010;42:658-60.

37. Mells GF, Floyd JA, Morley KI, et al. Genome-wide association study identifies 12 new susceptibility loci for primary biliary cirrhosis. Nat Genet. 2011;43:329-32.

38. Nakamura M, Nishida N, Kawashima M, et al. Genome-wide association study identifies TNFSF15 and POU2AF1 as susceptibility loci for primary biliary cirrhosis in the Japanese population. Am J Hum Genet. 2012;91:721-8.

39. Juran BD, Hirschfield GM, Invernizzi P, et al. Immunochip analyses identify a novel risk locus for primary biliary cirrhosis at $13 q 14$, multiple independent associations at four established risk loci and epistasis between $1 \mathrm{p} 31$ and $7 \mathrm{q} 32$ risk variants. Hum Mol Genet. 2012;21:5209-21.

40. Liu JZ, Almarri MA, Gaffney DJ, et al. Dense fine-mapping study identifies new susceptibility loci for primary biliary cirrhosis. Nat Genet. 2012;44:1137-41.
41. Cordell HJ, Han Y, Mells GF, et al. International genome-wide meta-analysis identifies new primary biliary cirrhosis risk loci and targetable pathogenic pathways. Nat Commun. 2015;6:8019.

42. Kawashima M, Hitomi Y, Aiba Y, et al. Genome-wide association studies identify PRKCB as a novel genetic susceptibility locus for primary biliary cholangitis in the Japanese population. Hum Mol Genet. 2017;26:650-9.

43. Qiu F, Tang R, Zuo X, et al. A genome-wide association study identifies six novel risk loci for primary biliary cholangitis. Nat Commun. 2017;8:14828.

44. Mungall AJ, Palmer SA, Sims SK, et al. The DNA sequence and analysis of human chromosome 6. Nature. 2003;425:805-11.

45. Umemura T, Ota M. Genetic factors affect the etiology, clinical characteristics and outcome of autoimmune hepatitis. Clin J Gastroenterol. 2015;8:360-6.

46. Ercilla G, Pares A, Arriaga F, et al. Primary biliary cirrhosis associated with HLA-DRw3. Tissue Antigens. 1979;14:449-52.

47. Donaldson PT, Baragiotta A, Heneghan MA, et al. HLA class II alleles, genotypes, haplotypes, and amino acids in primary biliary cirrhosis: a large-scale study. Hepatology. 2006;44:667-74.

48. Invernizzi P, Selmi C, Poli F, et al. Human leukocyte antigen polymorphisms in Italian primary biliary cirrhosis: a multicenter study of 664 patients and 1992 healthy controls. Hepatology. 2008;48:1906-12.

49. Li M, Zheng H, Tian QB, et al. HLA-DR polymorphism and primary biliary cirrhosis: evidence from a meta-analysis. Arch Med Res. 2014;45:270-9.

50. Umemura T, Joshita S, Ichijo T, et al. Human leukocyte antigen class II molecules confer both susceptibility and progression in Japanese patients with primary biliary cirrhosis. Hepatology. 2012;55:506-11.

51. Zhao DT, Liao HY, Zhang X, et al. Human leucocyte antigen alleles and haplotypes and their associations with antinuclear antibodies features in Chinese patients with primary biliary cirrhosis. Liver Int. 2014;34:220-6.

52. Clemente MG, Frau F, Bernasconi M, et al. Distinctive HLA-II association with primary biliary cholangitis on the Island of Sardinia. United European Gastroenterol J. 2017;5:527-31.

53. Yasunami M, Nakamura $\mathrm{H}$, Tokunaga $\mathrm{K}$, et al. Principal contribution of HLA-DQ alleles, DQB1*06:04 and DQB1*03:01, to disease resistance against primary biliary cholangitis in a Japanese population. Sci Rep. 2017;7:11093.

54. Alric L, Fort M, Izopet J, et al. Genes of the major histocompatibility complex class II influence the outcome of hepatitis $C$ virus infection. Gastroenterology. 1997;113:1675-81.

55. de Gruij1 TD, Bontkes HJ, Walboomers JM, et al. Immune responses against human papillomavirus (HPV) type 16 virus-like particles in a cohort study of women with cervical intraepithelial neoplasia. I. Differential T-helper and IgG responses in relation to HPV infection and disease outcome. J Gen Virol. 1999;80(Pt 2):399-408.

56. Hendel H, Caillat-Zucman S, Lebuanec H, et al. New class I and II HLA alleles strongly associated with opposite patterns of progression to AIDS. J Immunol. 1999;162:6942-6.

57. Thursz MR, Kwiatkowski D, Allsopp CE, et al. Association between an MHC class II allele and clearance of hepatitis B virus in the Gambia. N Engl J Med. 1995;332:1065-9.

58. Hildesheim A, Wang SS. Host and viral genetics and risk of cervical cancer: a review. Virus Res. 2002;89:229-40.

59. Selmi C, Ross SR, Ansari AA, et al. Lack of immunological or molecular evidence for a role of mouse mammary tumor retrovirus in primary biliary cirrhosis. Gastroenterology. 2004;127:493-501.

60. Meylan F, Richard AC, Siegel RM. TL1A and DR3, a TNF family ligand-receptor pair that promotes lymphocyte costimulation, mucosal hyperplasia, and autoimmune inflammation. Immunol Rev. 2011;244:188-96. 
61. Pulickal AS, Hambleton S, Callaghan MJ, et al. Biliary cirrhosis in a child with inherited interleukin-12 deficiency. J Trop Pediatr. 2008;54:269-71.

62. Hirschfield GM, Gershwin ME, Strauss R, et al. Ustekinumab for patients with primary biliary cholangitis who have an inadequate response to ursodeoxycholic acid: a proof-of-concept study. Hepatology. 2016;64:189-99.

63. Juran BD, Atkinson EJ, Larson JJ, et al. Carriage of a tumor necrosis factor polymorphism amplifies the cytotoxic T-lymphocyte antigen 4 attributed risk of primary biliary cirrhosis: evidence for a gene-gene interaction. Hepatology. 2010;52:223-9.
64. Miozzo M, Selmi C, Gentilin B, et al. Preferential $\times$ chromosome loss but random inactivation characterize primary biliary cirrhosis. Hepatology. 2007;46:456-62.

65. Invernizzi P, Miozzo M, Battezzati PM, et al. Frequency of monosomy $\mathrm{X}$ in women with primary biliary cirrhosis. Lancet. 2004;363:533-5.

66. Selmi C, Cavaciocchi F, Lleo A, et al. Genome-wide analysis of DNA methylation, copy number variation, and gene expression in monozygotic twins discordant for primary biliary cirrhosis. Front Immunol. 2014;5:128. 